\title{
Factors Associated with Occupational Stress and Their Effects on Organizational Performance in a Sudanese University
}

\author{
Ahlam B. El Shikieri ${ }^{1}$, Hassan A. Musa ${ }^{2}$ \\ ${ }^{1}$ Faculty of Applied Medical Sciences, Taibah University, Medina, Saudi Arabia \\ ${ }^{2}$ The National Ribat University, Khartoum, Sudan \\ Email: dn7shiki@hotmail.com
}

Received October 31 ${ }^{\text {st }}$, 2011; revised November 21 ${ }^{\text {st }}$, 2011; accepted December $8^{\text {th }}$, 2011

\begin{abstract}
Occupational stress has a significant impact on student learning and thereby on the contribution that such institutions can make to society. This affects organizational performance by reducing productivity and efficiency which affect the organization negatively. The aim of the current study was to determine the factors associated with occupational stress and their relationship with organizational performance at one of the private universities in Sudan. A total of 150 male and female employees from different departments and with various educational levels in the main building of the university were randomly selected. Data was collected using a questionnaire with background questions, job stressors such as role conflict and ambiguity, lack of participation in decision making, lack of authority, workload, unsatisfactory working conditions and interpersonal relationships, and statements about the effect on organisational performance. Questions were based on three- and four-point scale. Responses were grouped in terms of scores to show the level of job stress. Descriptive statistics was carried out using SPSS programme. Results indicated that on average the employees experienced high degree of job stress. Job stressors affected the general physical health of employees, their job satisfaction and performance as well as their commitment negatively. Similar findings were reported in other studies. The study recommended that the university needs to elevate the situation and resolve all the factors affecting the employees by for example increasing the number of staff needed to perform the tasks and/or decreasing the number of students enrolled.
\end{abstract}

Keywords: Higher Education; Occupational Stress; Organizational Performance; Sudan

\section{Introduction}

Stress is a prevalent problem in modern life (Smith, 2000; Chang \& Lu, 2007). In 1964, Selye was the first to use the term "stress" to describe a set of physical and psychological responses to adverse conditions or influences (cited from Fevre et al., 2003). Occupational stress can be defined as a disruption of the emotional stability of the individual that induces a state of disorganization in personality and behaviour (Nwadiani, 2006). A stressor may be defined as any "demand made by the internal or external environment that upsets a person's balance and for which restoration is needed" (Herbert, 1997; Larson, 2004). Job stressors may refer to any characteristic of the workplace that poses a threat to the individual (Bridger et al., 2007). They affect organizational performance by reducing productivity and efficiency which affect the organization negatively (Dua, 1994; Brown \& Uehara, 2008; Reskin, 2008).

\section{Theories of Occupational Stress}

There are several theories of occupation stress, in this section, the "person-environment fit theory, the "demand-control" theory and the "cybernetic and systems" theory will be the selected theories since they are prevalent and central to the literature on occupational stress (Fevre et al., 2003). Moreover, they are representative of the range of theories in that they tend to emphasise various sources and interactional models for the induction of stress as well as different outcome measures for the management of stressors (Fevre et al., 2003).

\section{Person-Environment (PE) Fit Theory}

According to the PE fit theory, stress and stressors are not defined in terms of either the individual or the environment, but rather in terms of the degree to which there is "misfit" between the two (Kenny, 1999; Fevre et al., 2003).

The outcome set of PE fit theory consists of the individual's potential reactions to misfit, which can be characterised as either coping or defense (Kenny, 1999; Rees \& Redfern, 2000). Coping and defense are both potentially adaptive, neither being necessarily better or more effective than the other.

\section{Demand-Control Theory}

The demand-control theory concerns the joint effects of job demands and job control on the employee well being (Kenny, 1999). According to Karasek's job demand-control model, strain occurs when high job demands combine with low opportunity to influence tasks and procedures, resulting in poor employee health and low job satisfaction (Bridger et al., 2007). Heavy workload (McKenna et al., 2002; Nwadiani, 2006), infrequent rest breaks, long working hours and shift work; hectic and routine tasks that have little inherent meaning, do not utilize workers' skills, and provide little sense of control (Fairbrother \& Warn, 2003). Locus of control and self-efficacy may have a major impact on perceived stressors and resultant stress (Kenny, 1999; Fevre et al., 2003; Love et al., 2007). Thus, an increase in control is positively correlated with job satisfaction (Kenny, 1999). 
According to the demand theory, demand is subdivided into workload, work hazards, physical and emotional demands and role conflict (Kenny, 1999; Love et al., 2007). For stress to exist, the demand from the environment (the job) versus the capability of the individual (the employee) will typically be considerably out of balance (Larson, 2004).

\section{Cybernetic and Systems Theory}

Cybernetics has been defined as a science of communication and control in man and machine; an epistemological foundation for personal and social change, which focuses on mental process, whereby individuals monitor their psychological and physiological reactions to various stressors (Kenny, 1999; Fevre et al., 2003). Cybernetic theory deals with the response of systems to information using feedback. The theory emphasises wholeness and the interaction of component parts. It incorporates organisation as unifying principles as well as incorporates nonlinear theories of causation and is based upon a circular epistemology (Kenny, 1999).

\section{Possible Causes of Stress in Higher Education}

Academic staff has a major role to play in achieving the objectives of the institution (Rowley, 1996). The performance of the staff, both as teachers and researchers and also as managers, determines to a large extent, the quality of the student experience of higher education and has a significant impact on student learning and thereby on the contribution that such institutions can make to society (Rowley, 1996). Responsibility for others is often associated with significant job stress. This happens because the individual is spending significant amounts of time interacting with others, attending meetings, and trying to work with and motivate others to meet deadlines and schedules. Responsibility for others can be particularly stressful for managerial and professional workers such as teachers (Gmelch \& Burns, 1994; Larson, 2004).

The stress experienced by different occupation types and job roles has been discussed in many studies with a number of different occupations being described as experiencing above average levels of stress, such as teachers (McCormick, 1997; Johnson et al., 2005; Brown \& Uehara, 2008). In a study by Baker (2004), it was reported that teachers had higher levels of stress at work, almost double the rate (40\%) when compared with other professions. A recent survey carried out by the Association of University Teachers found that $69 \%$ of academic and related staff found their job stressful and 50\% reported psychological distress (cited from Venables \& Allender, 2006). Similar findings were reported elsewhere (e.g. Gmelch \& Burns, 1994).

Stress is however not experienced uniformly by teachers, but varies from one individual to another (McCormick, 1997). This depends among other things, on the individual characteristics such as social support, coping strategies and individuals with Type A personality (Dua, 1994; Herbert, 1997). The latter individuals underestimate the time required to accomplish tasks and, therefore, experience time pressures. They work quickly and show impatience and decreased work performance if forced to work slowly (Sadri, 1997). Type As ignore, suppress or deny physical or psychological symptoms while working under pressure, and report such symptoms only when the work is finished (Daft, 2006). In addition, they works harder and experience physiological arousal when a task is perceived as challenging; express hostility and irritation in response to a threat; and need to be in control of the immediate environment to such an extent that a lack of control may elicit a hostile competitive response (Sadri, 1997).

Stress is not value-free, and for some teachers, coping with occupational stress may be associated with success, and "failing to cope” associated with failure (McCormick, 1997). McDonald and Korabik found that male managers reported coping strategies which can be categorized as "avoidance/withdrawal", while female managers reported that they were more likely to talk to others and seek social support than male managers (cited from Lim \& Teo, 1996).

Teaching is an occupation that demands many roles (McCormick, 1997). Role demands can become stressful for a teacher for many reasons; for instance when organisational members' expectations about a teacher's behaviour are unclear (role ambiguity) (Koustelios et al., 2004; Nwadiani, 2006). Role ambiguity refers to the uncertainty, on the part of employees, about key requirements of their jobs, and about how they are expected to behave in those jobs (Nhundu, 1999; Koustelios et al., 2004). Role ambiguity can result from deficient information available (Conley \& Woosley, 2000). The former could lead to lower performance in some jobs, simply because workers do not know how to direct their efforts most effectively (Conley \& Woosley, 2000) and is associated with job dissatisfaction (Fairbrother \& Warn, 2003; Bridger et al., 2007).

In addition, role demands are stressful when meeting one set of expectations makes it more difficult to meet other expectations (role conflict) (Koustelios et al., 2004; Johnson et al., 2005). Role conflict occurs when different groups or persons with whom an individual must interact (e.g. family, members of that person's group) hold conflicting expectations about that individual's behaviour (Nwadiani, 2006; Chang \& Lu, 2007). Role conflict can result from inconsistent information (Conley \& Woosley, 2000). It is important to note that several studies have revealed that both role conflict and role ambiguity are associated with low satisfaction, absenteeism, low involvement, low expectancies and task characteristics with a low motivating potential and tension, which all affect the productivity and efficiency at the organisation (Conley \& Woosley, 2000; Manshor et al., 2003; Koustelios et al., 2004; Nwadiani, 2006; Chang \& $\mathrm{Lu}, 2007)$.

Furthermore, role demands could be stressful when they are excessive (role overload) (Johnson et al, 2005). For instance, academic overload comes when teachers experience increased responsibilities (Stress, 2008). The daily interactions with students and co-workers and the incessant and fragmented demands of teaching often lead to overwhelming pressures and challenges, which may lead to stress (Brown \& Uehara, 2008). Universities are particularly vulnerable to these adverse effects of stress on staff, largely because of the recent dramatic increase in workloads, plus the past decade of rapid change and consequent reformulations of goals and activities which have accompanied these changes in several communities (e.g. Sharpley et al., 1996).

There are many examples of intensified teaching workload. These included the expansion of student teacher ratios due to understaffing and different tasks being added to the teacher's workday, many of which were administrative in nature (Gmelch \& Burns, 1994; Nwadiani, 2006; Timms et al., 2007). A study indicated that males scored significantly higher than females on a number of scales related to occupational stress, namely work 
relationships, overload, and the overall job stress index (Vakola \& Nikolaou, 2005). In another study, class numbers which had multiplied fivefold in some cases and tenfold or more in others, had led teachers to be over-stressed (Farrugia, 1996). Some members experienced "increased content of jobs (often through understaffing), less time for rest breaks, balancing more simultaneous demands, deadline tightening and the concept of working until the job is done" (Noblet, 2003; Johnson et al., 2005; Timms et al., 2007).

In many cases employee found themselves in a position where work had to be taken home in order to fulfil and sustain a professional standard; this reduces the possible opportunity for restorative psychological detachment from the job (Timms et al., 2007). Education administrators for instance, hold leadership positions with significant responsibility. Most of them found working with students extremely rewarding, but as the responsibilities of administrators have increased in recent years, so has the stress (Department of Labour, 2008). Research studies have also identified several sources of stress for educational administrators in Zimbabwe, chief among them are role overload, lack of autonomy, responsibility for others, interpersonal relationships, lack of recognition, staff evaluation, and inadequate resources (Nhundu, 1999).

Whereas the stress of overload is unhealthy for the individual, heavy employee workloads may be beneficial for the organisation. Qualitative overload does not appear to be a major problem among the respondents to the study. This situation often results in conflicts between employees and employers over workloads. Variety in the work environment enhances interest and challenge and has been reported as a key factor in employee job satisfaction (Larson, 2004). This situation is not just reported in developed countries. For instance, the significant factors influencing academic stress among lecturers in Nigerian universities included: workload, strike and school interruption, delay and irregular payment of salary and lack of instructional facilities, unmanageable classroom student population, unsteady school calendar, preparation of examination results, invigilation of examinations, state of lecturers office accommodation and lack of facilities for research (Nwadiani, 2006). Similar findings were reported in other countries such as China (e.g. Liu \& Oppenheim, 2006).

Furthermore, studies have indicated that "continuous depletion of resources would lead to negative load effects (e.g. fatigue) and, ultimately in the absence of recovery, to exhaustion, losses of function, and physical and mental impairment” (Dua, 1994; Nwadiani, 2006; Timms et al., 2007; Brown \& Uehara, 2008). Exhaustion is an emotional, cognitive and physical experience of being over extended and overwhelmed and is the basic stress experience for most individuals (Timms et al., 2007). Following the experience of extreme exhaustion, individuals will be disengaged. Disengagement is a feeling of distancing from and devaluing of the work experience. Workers suffering from disengagement will become negative about their work and the people associated with it (Timms et al., 2007).

Research has shown that organisational change, such as downsizing, implementation of new equipment or plant and restructuring, can and often does lead to stress and increases in injury/illness (Rees \& Redfern, 2000; Savery \& Luks, 2001; Morris et al., 2006). In a study conducted by Sharpley and coworkers (1996) on university staff in Monash University, Australia, the most commonly reported sources of job stress were (in order of frequency): "lack of regular feedback about how well I am doing my job”; "lack of promotion opportunities”; "uncertainty about how amalgamations will influence me"; "overwork"; "being expected to do too much in too little time"; "lack of necessary equipment and/or infrastructure support". Overall the university employees were suffering from moderate job stress level in that study (Sharpley et al., 1996). Similar findings were reported elsewhere e.g. Rees \& Redfern (2000) and Reskin (2008). Increases in class size, static budgets, searching for alternative sources of finance for funding research, imposed forms of review and accountability, lack of tenure all contribute to the potential for an increase in conflict and negative stress outcomes among members of the profession (Gmelch \& Burns, 1994; Sotirakou, 2004).

Furthermore, several studies had revealed that poor social environment and lack of support or help from co-workers and supervisors are considered job stressors (Dua, 1994; Johnson et al., 2005; Stress, 2008). Selye (1974) suggested that learning to live with other people is one of the most stressful aspects of life (cited from Manshor et al., 2003). Conflicting or uncertain job expectations, too much responsibility (Rees \& Redfern, 2000), too many "hats to wear", being undervalued and the threat of redundancy are all some of the sources of occupation stress (Fairbrother \& Warn, 2003; Manshor et al., 2003). Job insecurity and lack of opportunity for growth, advancement, or promotion; rapid changes for which workers are unprepared are other aspects of occupation stress. Unpleasant or dangerous physical conditions such as crowding, noise, air pollution, or ergonomic problems (Smith, 2000; Fairbrother \& Warn, 2003; Manshor et al., 2003; Reskin, 2008) as well as unrealistic deadlines are known to cause occupation stress (Rees \& Redfern, 2000; Johnson et al., 2005; LeGrande, 2008).

Recent studies of organisational management have addressed the significance of organisational culture on stress formation, since sources of stress can depend on the characteristics of the culture existed in organisations (Chang \& Lu, 2007). Negative culture based on blame for and denial of problems, or misguided practical jokes or initiation ceremonies are shown to be associated with stress resulting from work relationships (Rees \& Redfern, 2000). For instance, teachers who moved into unfamiliar cultures, acculturative stress could cause lowered mental health (e.g., confusion, anxiety, depression) and feelings of alienation; those who feel marginalized can become highly stressed (Brown \& Uehara, 2008). Teachers from very different cultures might neither understand nor appreciate the cultural differences of the communities in which they are placed. This could then lead to additional stress, which eventually leads to high attrition (Brown \& Uehara, 2008). Job stress also occurs when conditions on a job inhibit, stifle, or thwart the attainment of expectations and goals.

It is important to note that not all job stressors are bad because a certain amount of job stress has been shown to improve both effectiveness and performance (Larson, 2004). For example, a promotion is an opportunity and can be a challenging and exciting experience. However, mismanaged organisational stress can produce individual stresses and strains that are detrimental both to the individual and to the organisation. Because stress is additive, the more stressors in the work environment, the higher the individual's overall job stress level (e.g. Chevaillier, 2000; Larson, 2004).

In an Australian study conducted by Savery and Luks (2000), the males in the sample generally attributed significantly more stress than the females and were more likely to work excessive 
hours than women whereas women are more focused on intrinsic rewards and rely less on promotion and salary than men and, therefore, they spend less time at the office. In another study by Gmelch \& Burns (1994) in the United States, women academics were found to experience significantly more stress than their male counterparts in the areas of task-based and professional identity. Similar findings were reported by the Singaporean study of human resource professionals, it was reported that females experienced significantly more stress as a result of organisational politics than their male counterparts (Lim \& Teo, 1996).

Similar findings were reported in the United Kingdom by Fotinatos-Ventouratos \& Cooper (2005) who found that in terms of "relationships with other people" females reported a higher mean score, indicating this to be a source of job pressure. de Smet and co-workers (2005) showed that, adjusting for age, education and occupational groups, men perceived less psychological job demand than women did (although marginal). Gender-based differences appeared to be larger for job control, with men perceiving higher control at work than women. The deficit of job control in females, however, increased towards less qualified occupations. Job strain was less prevalent in men than in women, without apparent regional heterogeneity (de Smet et al., 2005).

Age has been shown in some studies to have a curvilinear relationship; the older employees being more satisfied than the younger ones (Punnett et al., 2007). In a study conducted in Australia by Dua (1994), younger staff reported more job stress than older staff. That was attributed to the idea that as people get older they become more experienced and more worldlywise. The study conducted in Malaysia by Manshor and coworkers (2003) also indicated that age was significantly correlated with sources of stress, in particular with workloads. Workloads become intolerable to a certain range of ages.

\section{Stress in the Higher Education System and Its Effects on Organizational Performance}

The stress experienced by different occupation types and job roles has been discussed in many papers with a number of different occupations being described as experiencing above average levels of stress, such as teachers (McCormick, 1997; Johnson et al., 2005; Brown \& Uehara, 2008). Furthermore, role demands could be stressful when they are excessive (role overload) (Johnson et al, 2005). For instance, academic overload comes when teachers experience increased responsibilities (Stress, 2008). The daily interactions with students and co-workers and the incessant and fragmented demands of teaching often lead to overwhelming pressures and challenges, which may lead to stress (Brown \& Uehara, 2008).

Several studies have revealed that both role conflict and role ambiguity are associated with low satisfaction, absenteeism, low involvement, low expectancies and task characteristics with a low motivating potential and tension, which all affect the productivity and efficiency at the organisation (Conley \& Woosley, 2000; Koustelios et al., 2004; Nwadiani, 2006; Chang and Lu, 2007). Role ambiguity refers to the uncertainty, on the part of employees, about key requirements of their jobs, and about how they are expected to behave in those jobs (Nhundu, 1999; Conley \& Woosley, 2000; Koustelios et al., 2004). Role conflict occurs when different groups or persons with whom an individual must interact hold conflicting expectations about that individual's behaviour and can result from inconsistent information (Koustelios et al., 2004; Johnson et al., 2005; Nwadiani, 2006; Chang \& Lu, 2007).

Research has shown that organizational change, such as downsizing, implementation of new equipment or plant and restructuring, can and often does lead to stress and increases in injury/illness (Savery \& Luks, 2001; Morris et al., 2006). In a study conducted by Sharpley and co-workers (1997) on university staff, the most commonly reported sources of job stress were (in order of frequency): "lack of regular feedback about how well I am doing my job"; "lack of promotion opportunities"; "uncertainty about how amalgamations will influence me"; "overwork"; "being expected to do too much in too little time"; "lack of necessary equipment and/or infrastructure support". Lack of participation by workers in decision making, poor communication in the organization (Work Safe, 2006; Reskin, 2008), lack of family friendly policies, poor social environment and lack of support or help from co-workers and supervisors as well as at home as considered job stressors (Dua, 1994; Johnson et al., 2005; Stress, 2008).

Unpleasant or dangerous physical conditions such as crowding, noise, air pollution, or ergonomic problems (Smith, 2000; Fairbrother \& Warn, 2003; Manshor et al., 2003; Reskin, 2008) as well as unrealistic deadlines, low levels of support from supervisors are known to cause occupation stress (Johnson et al., 2005; Work Safe, 2006). Selye (1974) suggested that learning to live with other people is one of the most stressful aspects of life (cited from Manshor et al., 2003). For teachers who move into unfamiliar cultures, acculturative stress can cause lowered mental health (e.g., confusion, anxiety, depression) and feelings of alienation; those who feel marginalized can become highly stressed. In addition, stress is created when politics rather than performance affect organizational decisions.

Office politics can be profoundly stressful for professional and white-collar workers (Larson, 2004; Chang \& Lu, 2007). Working in a large, hierarchical, bureaucratic organization where employees have little control over their jobs can be very stressful. A supervisor's autocratic management style often results in high turnover, high absenteeism, and low morale among their subordinates. A lack of effective communication within an organization, excessive red tape, and seemingly endless paperwork was very stressful for internal auditors (Gmelch \& Burns, 1994; Larson, 2004; Vakola \& Nikolaou, 2005; Chang \& Lu, 2007; Brown \& Uehara, 2008).

Stress is associated with impaired individual functioning in the workplace (Smith, 2000) and a major impediment to organizational success (Noblet, 2003). More recent estimates suggest that some 91.5 million working days are lost each year through stress-related illness (Smith, 2000). Negative effects include reduced efficiency, decreased capacity to perform, dampened initiative and reduced interest in working, increased rigidity of thought, a lack of concern for the organisation and colleagues, and a loss of responsibility (Dua, 1994; Fairbrother \& Warn, 2003).

Moreover, stress is associated with reduction in output, product quality, service or morale (Ben-Bakr et al., 1995; Brown \& Uehara, 2008), increased wages/overtime payments, organisational sabotage (Work Safe, 2006), all which add costs to the organisation (Lim \& Teo, 1996; Brown \& Uehara, 2008). Teachers in particular represent a large proportion of work-related stress claims. These claims cost school systems billions of dollars in medical costs, substitute teachers, and disability payments 
(Brown \& Uehara, 2008). All these will affect the application of TQM in the higher education.

Literature search revealed no previous studies conducted at any governmental or private universities in the Sudan aiming at assessing the factors contributing to occupational stress at the university. Thus the aim of the current study was to determine the factors associated with occupational stress and their relationship with organizational performance at one of the private Sudanese universities.

\section{Research Methodology}

\section{Study Area}

A private university, where students pay an annual fee for their studies, was selected as the study area. In answering the research questions, a cross-sectional, descriptive facility-based study design was chosen. Due to limited resources in terms of time, costs, and access, this study design was selected. Ethical permission to carry out the current study was obtained from the Academic Affairs' Officer at the university. The study was conducted between February and April 2009.

\section{Study Sample}

Staff working at the central building of the university was randomly selected. Employees from various departments, specializations and with different duties were selected. Both males and female employees from different age groups i.e. less than 20 years to above 50 years were eligible for inclusion in the study. Employees were then randomly selected and were assured that the data collected would be confidential and that they had the right to withdraw from the study at any time they wished without any forces placed on them.

\section{Data Collection Method}

Data was obtained from structured well designed previously pre-tested questionnaire. It took approximately three months to design the English version of the questionnaire which was then translated into the local Arabic Language before distribution. Employees who were illiterate or have low education levels (i.e. primary and senior schooling) did not fill the questionnaires. In such cases, the researcher asked the questions verbally and the respondents' answers were written. All the questionnaires were then checked by the researcher in the presence of the employee and those missed or double-checked responses were correctly completed.

The questions included were collated mostly from previous studies about occupational stress and impact of stress on organisational performance, where both the reliability and validity of the data collection tool were tested (e.g. Dua, 1994; Manshor et al., 2003; Chen et al., 2006; Venables \& Allender, 2006). Background information about the employees was assessed by asking questions such as the gender, marital status, education level and type of contract. About 9 questions were used to determine the general characteristics of the employees. Primary education whether complete and/or incomplete were grouped as primary education; senior complete and incomplete were group as senior education; any higher education was termed as postgraduate education. The number of years working in the university were summarised as either between $1-4$ or $5-9$. In terms of the number of staff supervised, results were either none (zero), 1 20 , and $>20$ employees. These variables would appear in such format in the data analysis section.

Questions were grouped into sections according to the job stressor they assess. There was a section about role ambiguity and role conflict; promotion, development, training opportunities and feedback; participation in decision making and authority; workload; working condition and interpersonal relations. All the questions were close ended except the two last questions which left scope for the participants to add any other comments about the factors associated with occupational stress. The questions about job stressors were based on three-point Likert scale such that the employee would chose between "not at all true", "somewhat true" and "completely true". Similar methods were reported previously (e.g. Dua, 1994; Sharpley et al., 1996).

In terms of the effects on organisational performance such as the number of days absent from work, the four-point Likert scale was either "never (or zero)", “1 - 2”, “3 - 4" and “> 4 times” during the last month or six month. Statement that assess both role ambiguity and conflict include "I work with groups of people who expect many different related things from me", "I work with groups of people who expect many different unrelated things from me", "I often perform tasks that are too boring, I have to do things that should be done differently". Overall, the questionnaire included about 30 statements about role ambiguity and conflict.

Workload as a job stressor was assessed in terms of number of lectures per week, supervision of students, administrative work and number of hours working per day. The presence of career development opportunities was determined by formalising questions about promotion opportunities and the presence or lack of offers of training and development opportunities. The questionnaire included about 20 statements assessing workload. Reward, recognition, training opportunities and feedback were assessed by the adequacy of rewards, clarity of expectations, sufficiency of recognition and how supervisors evaluate the performance. The questionnaire included about 8 statements to assess this job stressor.

The study also included questions about the organisational culture such politics in organisations, participation in decisionmaking and communication styles similar methods were undertaken previously e.g. Manshor et al. (2003) and Chang \& Lu (2007). The questionnaire included about 7 statements assessing participation in decision making and authority. In addition, questions about the working conditions such as surroundings such as technology, resources, air quality, lighting, decoration, tidiness, noise, furniture and personal space (e.g. Manshor et al., 2003; Venables \& Allender, 2006). The questionnaire included 15 statements to assess working conditions. Perceptions of how staff is treated and supervisor's attitude included statements such as "I think the university looks after its employees in every aspect". The questionnaire included about 4 statements assessing the interpersonal relationships.

Furthermore, physical health, job performance and satisfaction, job commitment were used to assess the impact of occupational stress on organisational performance. In terms of physiccal health, statements such as the number of days absent from work due to medical problem and number of times had prolonged sleepless nights. Assessment of statements related to physical health was designed so as to include the effect within the last month or within the previous six months. This way was chosen since there might not be any effects on health during the last month. In terms of job performance and satisfaction, statement such as "working with little efficiency compared to my 
first months of appointment in this university" and "being proud to tell others that I am part of this university" were included. Job commitment was assessed by including statements such as "If had a chance to advance professionally by going to another university, would go" and "I feel very little loyalty to my discipline”. The questionnaire included about 43 statements assessing the impact of job stressors on organisational performance.

\section{Statistical Procedures}

Inferential statistical analysis was carried out by using SPSS for WINDOWS (version 13; SPSS Inc, Chicago). Descriptive statistics were used to determine the mean and standard deviation. Frequencies were used to determine the number and percent of participants suffering from job stressors and for background information about the employees. Spearman R correlation coefficient was used to determine the extent to which values of two variables are proportional to each other. In such case, it was used to assess the association between job stressors and organisational performance. Significant differences were accepted at $P$-value of $\leq 0.05$.
Job stressors reported by more than $40 \%$ of the employees were only presented on the result tables. In scoring, the average score was calculated for each subject job stress and then this score was re-coded as low job stress (indicated by the average score of 1.00 to 1.50 ), medium job stress (1.51 to 2.00), or high job stress (2.01 to 3.00). The overall mean score for the subcategories of job stressor was then calculated. Previous studies followed similar way of scoring (e.g. Dua, 1994; Sharpley et al., 1996).

\section{Results}

\section{Background Information}

The total number of approached participants was 160 of whom 150 were selected. Thus the response rate was $93.8 \%$. A large number of participants was aged above 30 years and most of them were men $(P<0.001$, Table 1). Employees from different types of work were included (Table 2). A large number of them were either administrators or lecturers comprising $72 \%$ of the whole population studied. On average, the participants worked $4.5 \pm 2$ years.

Table 1.

Demographic characteristics of the staff at the private Sudanese university. Number and percent of males and females included are shown.

\begin{tabular}{llll}
\hline Variable & Males $(\mathrm{n}=87)$ & Females $(\mathrm{n}=63)$ & Total $(\mathrm{n}=150)$ \\
\hline Age group & & & \\
$-21-30$ & $9(10.3 \%)$ & $24(38.1 \%)$ & $33(22 \%)$ \\
$-31-40$ & $74(85.1 \%)$ & $38(60.3 \%)$ & $112(74.7 \%)$ \\
$->41$ & $4(4.6 \%)$ & $1(1.6 \%)$ & $5(3.3 \%)^{* * * *}$ \\
Education Level & & & \\
- Primary education & $6(6.8 \%)$ & $13(20.7 \%)$ & $19(12.7 \%)$ \\
- Senior education & $16(18.4 \%)$ & $3(4.8 \%)$ & $19(12.7 \%)$ \\
- Diploma certificate & $12(13.8 \%)$ & $3(4.8 \%)$ & $15(10 \%)$ \\
- Bachelor certificate & $25(28.7 \%)$ & $28(44 \%)$ & $53(35.3 \%)$ \\
- Postgraduate education & $28(32.2 \%)$ & $16(25.4 \%)$ & $44(29 \%)$ \\
Marital status & & & \\
- Single & $34(39.1 \%)$ & $37(58.7 \%)$ & $71(47.3 \%)$ \\
- Married & $52(59.8 \%)$ & $26(41.3 \%)$ & $78(52 \%)$ \\
- Divorced & $1(1.1 \%)$ & $0(0 \%)$ & $1(0.7 \%)^{*}$ \\
\hline
\end{tabular}

${ }^{*} \mathrm{P}=.05 ;{ }^{* * * *} \mathrm{P}<.001$.

Table 2.

The type of work, contract type, number of years and number of staff supervised by participants at the private Sudanese university.

\begin{tabular}{llll}
\hline Variable & Males $(\mathrm{n}=87)$ & Females $(\mathrm{n}=63)$ & Total $(\mathrm{n}=150)$ \\
\hline Type of work & & & \\
- Administrators & $25(29 \%)$ & $24(38 \%)$ & $49(36.7 \%)$ \\
- Lecturers & $31(36 \%)$ & $22(35 \%)$ & $53(35.3 \%)$ \\
- Technicians & $9(10 \%)$ & $3(4.8 \%)$ & $12(8 \%)$ \\
- Workers & $22(25 \%)$ & $14(22.2 \%)$ & $36(24 \%)$ \\
Contract Type & & & \\
- Full Time & $31(35.6 \%)$ & $16(25.4 \%)$ & $47(31.3 \%)$ \\
- Part Time & $3(3.4 \%)$ & $0(0 \%)$ & $3(2 \%)$ \\
- Permanent & $48(55.2 \%)$ & $37(58.7 \%)$ & $85(56.7 \%)$ \\
- Temporary & $5(5.7 \%)$ & $10(15.8 \%)$ & $15(10 \%)^{*}$ \\
Number of years working & & & \\
- 1-4 & $32(37.7 \%)$ & $34(54 \%)$ & $86(44 \%)$ \\
- 5-9 & $55(63.1 \%)$ & $29(46 \%)$ & \\
Number of staff supervised & & & $104(69.3 \%)$ \\
- None & $54(62 \%)$ & $50(79.4 \%)$ & $38(25.4 \%)$ \\
$-1-20$ & $25(29 \%)$ & $13(20.6 \%)$ & $8(5.3 \%)^{* * *}$ \\
$->20$ & $8(9 \%)$ & $0(0 \%)$ & \\
\hline
\end{tabular}

${ }^{*} \mathrm{P}=.02 ;{ }^{* *} \mathrm{P}=.003 ;{ }^{* * *} \mathrm{P}=.002 ; \S$ Workers include drivers, gatekeepers and cleaners. 


\section{Job Stressors Affecting All the Employees Included $(\mathbf{n}=150)$}

"Lack of participation in decision making and lack of authority" were considered high degree job stress affecting most of the employees at the private university with a mean score of 2.32 (Table 3). This job stressor was on average reported by $81.8 \%$ of the employees. Moreover, within this job stressor, $92.7 \%$ of the employees reported that they had either "little chance/scope in contributing to decision making at institutional level in terms of academic policies" or "little chance/scope in contributing to decision making at faculty level in terms of academic policies” (Table 3). Moreover, lack of promotion, development and training opportunities and lack of job feedback were also considered high degree job stress with an overall mean score of 2.11 (Table 3). Employees (71.7\%) suffered from this stressor with $94 \%$ stating that "policies rather than performance determine who should be promoted in my department" followed by 90.7\% "not knowing how my supervisor evaluates my performance” (Table 3).

Table 3.

Job stressors and their sub-categories affecting employees at the private Sudanese university ( $\mathrm{n}=150)$ : \% of employees and Mean \pm sd are shown.

\begin{tabular}{|c|c|c|}
\hline Job stressors and their sub-categories & $\%$ of employees & Mean \pm sd \\
\hline \multicolumn{3}{|l|}{ Role conflict and Role ambiguity } \\
\hline - I work with group of people who expect many different related things from me & 90.0 & $2.07 \pm 0.51$ \\
\hline - I work with group of people who expect many different unrelated things from me & 73.3 & $1.79 \pm 0.53$ \\
\hline - I often perform tasks that are too boring & 62.7 & $1.67 \pm 0.55$ \\
\hline - I often receive assignments without the resources to complete them (e.g. staff, money etc.) & 52.0 & $1.60 \pm 0.64$ \\
\hline - I sometimes have to break a university rule or policy in order to carry out an assignment & 68.0 & $1.99 \pm 0.80$ \\
\hline - I have to do things that should be done differently & 94.7 & $2.31 \pm 0.57$ \\
\hline - In general I perform work that does not suit my values & 52.0 & $1.63 \pm 0.67$ \\
\hline - Receiving too much pressure from too many people & 92.0 & $2.25 \pm 0.59$ \\
\hline - Feeling to have to do things which you think are unethical & 60.7 & $1.75 \pm 0.70$ \\
\hline - There was more than one time sudden unplanned change & 61.4 & $1.80 \pm 0.79$ \\
\hline - I have incompatible requests from different people & 48.7 & $1.53 \pm 0.59$ \\
\hline - I do not have a detailed written description of my job & 46.0 & $1.97 \pm 0.95$ \\
\hline - Percent within all categories & 66.8 & $1.86 \pm 0.66^{*}$ \\
\hline \multicolumn{3}{|l|}{ Promotion, development, training opportunities and feedback } \\
\hline - There is an unfair promotion system in the university & 68.7 & $2.09 \pm 0.84$ \\
\hline - There is an inadequate reward/recognition system & 62.7 & $1.97 \pm 0.85$ \\
\hline - The university lacks offers of training and development opportunities & 65.4 & $1.88 \pm 0.75$ \\
\hline - The university lack facilities for undertaking research & 72.0 & $2.00 \pm 0.75$ \\
\hline - Policies rather than performance determine who should be promoted in my department & 94.0 & $2.52 \pm 0.61$ \\
\hline - There is not a well-defined performance evaluation procedure which is implemented & 48.7 & $1.65 \pm 0.71$ \\
\hline - Not knowing how my supervisor evaluates my performance & 90.7 & $2.63 \pm 0.65$ \\
\hline - Percent within all categories & 71.7 & $2.11 \pm 0.74^{*}$ \\
\hline \multicolumn{3}{|l|}{ Participation in decision making and authority } \\
\hline - I have little chance/scope in contributing to decision making at faculty level in terms of academic policies & 92.0 & $2.45 \pm 0.64$ \\
\hline - I have little chance/scope in contributing to decision making at institutional level in terms of academic policies & 92.7 & $2.65 \pm 0.61$ \\
\hline - I have little chance/scope in contributing to decision making in my own department in terms of academic policies & 88.7 & $2.39 \pm 0.68$ \\
\hline - I have little chance/scope in contributing to decision making at faculty level in terms of academic policies & 92.0 & $2.45 \pm 0.64$ \\
\hline - I have little chance/scope in contributing to decision making at institutional level in terms of academic policies & 92.7 & $2.65 \pm 0.61$ \\
\hline \multicolumn{3}{|l|}{ Participation in decision making and authority } \\
\hline - I have little chance/scope in contributing to decision making in my own department in terms of academic policies & 88.7 & $2.39 \pm 0.68$ \\
\hline - I have little chance/scope in contributing to decision making at faculty level in terms of financial policies & 78.0 & $2.29 \pm 0.81$ \\
\hline - I have little chance/scope in contributing to decision making at institutional level in terms of financial policies & 73.3 & $2.31 \pm 0.87$ \\
\hline - I have little chance/scope in contributing to decision making in my own department in terms of financial policies & 81.4 & $2.38 \pm 0.64$ \\
\hline - Overall I have too little authority in my work & 82.7 & $2.37 \pm 0.76$ \\
\hline - Most people here make up their own rules & 65.3 & $1.73 \pm 0.60$ \\
\hline - Percent within all categories & 81.8 & $2.32 \pm 0.70^{*}$ \\
\hline
\end{tabular}




\begin{tabular}{|c|c|c|}
\hline \multicolumn{3}{|l|}{ Workload } \\
\hline - I have to submit my work in a tightening deadline & 76.0 & $1.90 \pm 0.61$ \\
\hline - The overall concept in the university is to work until the job is done & 92.7 & $2.37 \pm 0.62$ \\
\hline - I feel stressed because of the unrealistic deadlines & 86.0 & $2.06 \pm 0.58$ \\
\hline - More than three times you are asked to carry administrative work & 48.6 & $2.55 \pm 1.28$ \\
\hline - More than four working hours per day & 88.7 & $3.75 \pm 0.75$ \\
\hline - There is less time for rest breaks at work & 41.4 & $1.46 \pm 0.59$ \\
\hline - Job demands interfere with personal time & 73.3 & $1.87 \pm 0.63$ \\
\hline - This university really inspires the very best in me in the way of job performance & 96.0 & $2.35 \pm 0.56$ \\
\hline - Percent within all categories & 75.3 & $2.29 \pm 0.70^{*}$ \\
\hline \multicolumn{3}{|l|}{ Working condition } \\
\hline - I do not have an office & 48.7 & $1.99 \pm 0.98$ \\
\hline - There is not good air quality in the office & 46.0 & $1.99 \pm 0.96$ \\
\hline - There is not enough light in the office & 46.7 & $2.0 \pm 0.97$ \\
\hline - The office is not reasonably decorated & 46.0 & $1.93 \pm 0.92$ \\
\hline - The office is not tidy and cleaned regularly & 46.0 & $1.89 \pm 0.90$ \\
\hline - The office is not reasonably furnished & 46.0 & $1.97 \pm 0.95$ \\
\hline - There is not enough space in the office & 46.7 & $1.96 \pm 0.95$ \\
\hline - There is not a little noise which distract the work in the office & 46.3 & $1.83 \pm 0.87$ \\
\hline - The office is overcrowded & 45.3 & $1.93 \pm 0.91$ \\
\hline - Often, I find it difficult to agree with this university’s policies on important matters relating to its academic policies & 82.0 & $1.97 \pm 0.58$ \\
\hline - There is a lack of instructional facilities in our department & 78.0 & $2.01 \pm 0.67$ \\
\hline - There is a problem of understaffing in my department & 88.7 & $1.35 \pm 0.58$ \\
\hline - Percent within all categories & 55.5 & $1.90 \pm 0.85 *$ \\
\hline
\end{tabular}

${ }^{*}$ Overall mean score.

Furthermore, results revealed that role conflict and role ambiguity were a medium degree stress with an overall mean of 1.86 and affecting $66.8 \%$ of the employees. In this job stressor, $94.7 \%$ reported that "they have to do things that should be done differently" followed by 92\% "receiving too much pressure from too many people” (Table 3). Finally, working conditions were medium degree stress with a mean score of 1.9 and $55.5 \%$ were suffering from this stressor. "The problem of understaffing in my department" affected $88.7 \%$ of the employees in this job stressor category followed by $82 \%$ finding it "difficult to agree with this university's policies on important matters relating to its academic policies" (Table 3).

Furthermore, $75.3 \%$ of the employees complained from workload with an overall mean score of 2.29; thus making workload a high degree job stress (Table 3). Large percent of employees (96\%) within this stressor stated that "the university really inspires the very best in me in the way of job performance" followed by $92.7 \%$ of them reporting that "the overall concept in the university is to work until the job is done" (Table 3).

\section{The Impact of Job Stressors on Organisational Performance}

Job stress affected employees' physical health and that was shown by the large percent of employees (86\%) reporting that they "suffered more than two times from illness during last six months (e.g. muscle tension, nausea, vomiting, increased heart rate etc.)" and were "absent more than two days from work due to medical problem in the last six month”. There was an overall negative association between role conflict and ambiguity and the employees' physical health (Table 4). The influence of job stress on job performance and satisfaction was reported by most of the employees (91.1\%). Although, these employees were "proud to tell others that they are part of the university", most of them (90\%) were "working with little efficiency compared to their first month". Results indicated that as most of the people at the university make up their own rules and there was a lack of instructional facilities in their departments, the employees work with little efficiency compared to their first month of appointment in the university. On average, $81.7 \%$ of the employees reported that job stress affected their overall commitment to their job. Although, nearly all the employees (97.3\%) stated that they "cared about the future of the university" and were "willing to put in a great deal of effort beyond that normally expected in order to help the university to be successful", they showed little job commitment by reporting that there "is not too much to be gained by sticking with this university" and "if they had a chance to advance professionally by going to another university, they would go".

There was an overall negative association between role conflict and ambiguity and the employees' physical health. Moreover, a negative relationship was also found between the working conditions and physical health In terms of the promotion opportunities and feedback and interpersonal relationship, they affected the physical health of employees both negatively and positively. Furthermore, workload affected physical health both 
negatively and positively. Participation in decision making and authority correlated positively with employees' physical health (Table 4).

Role conflict and ambiguity, participation in decision making and authority as well as working conditions correlated positively with job performance and satisfaction. For example, results indicated that as most of the people at the university make up their own rules and there was a lack of instructional facilities in their departments, the employees work with little efficiency compared to their first month of appointment in the university (Table 4).

Promotion opportunities and feedback correlated both positively and negatively with job performance and satisfaction. For instance, as the university lacks offers of training and development opportunities, employees did not feel proud to tell others that they were part of the university. The same relationship was found between interpersonal relationships and job performance and satisfaction. As employees often perform tasks that were too boring, they felt very little loyalty to their discipline. Moreover, there were both negative and positive correlations between participation in decision making and authority and interpersonal relationships and job commitment (Table 4).

\section{Discussion}

Findings in a study conducted by others (e.g. Sharply et al, 1997; Noblet, 2003; Johnson et al., 2005; Timms et al., 2007) on university staff were similar to those shown in the current study. Unlike the study by Sharpley and others (1997) in which university employees suffered moderate job stress, the employees in the current study suffered high job stress level. Similar effects on the organisational performance were reported previously (e.g. Dua, 1994; Fairbrother \& Warn, 2003). Similar effects on the organisational performance were reported previ- ously (Dua, 1994; Fairbrother \& Warn, 2003). Role conflict and ambiguity had been shown to lead to lower performance in some jobs, simply because workers do not know how to direct their efforts most effectively (Nwadiani, 2006). Absenteeism would also affect the productivity and efficiency at the organisation negatively in several studies (Dua, 1994; Koustelios et al., 2004; Chang \& Lu, 2007). Employees are valuable assets of the organisation and they are responsible for the attraction of the external customers and increase the profitability of the institute. Focusing on employees, their needs and wants, would definitely increase their job satisfaction, performance and commitment and hence increase their output.

The university needs to elevate the situation and resolve all the factors affecting the employees. This could be achieved by constructing clear formal rules, policies and guidelines so that all the employees have to fulfil. In addition, the employees should have their detailed job descriptions so that they know their limits and be involved in decision making and have feedback about their performances. The university could either increase the number of staff needed to perform the tasks, decrease the number of students enrolled or increase the overall paid salaries to compensate for this stressor. These recommenddations might help in reducing the costs incurred when the trained, well experienced employee and/or the student leave the organisation. It is always more expensive to recruit new customers than keep the old ones (Daft, 2006). They could also serve as a base for achieving total quality management in the university.

This is considered the first well planned and designed study of its type to be conducted in Sudanese universities aiming at assessing the factors associated with occupational stress and their impact on organisational performance. The questionnaire was very detailed and comprehensive to the extent that $99 \%$ of

Table 4.

The impact of selected job stressors on organisational performance. Correlation coefficient and $P$-values $(<0.05)$ are shown.

\begin{tabular}{|c|c|c|}
\hline Job stressors and their sub-categories & r-value & $P$-value \\
\hline \multicolumn{3}{|l|}{ Physical health: Number of times you suffered from illness during the last month } \\
\hline \multicolumn{3}{|l|}{ Role conflict } \\
\hline - I work under incompatible policies and guidelines & 0.2 & 0.02 \\
\hline - I have incompatible requests from different people & -0.2 & 0.02 \\
\hline - I get regular feedback on how I am doing the job & -0.2 & 0.01 \\
\hline - I have little chance/scope in contributing to decision making at university level in terms of financial policies & -0.2 & 0.003 \\
\hline \multicolumn{3}{|l|}{ Workload } \\
\hline - I feel stressed because of the high cost of living which could not be met by my salary and expenses & 0.2 & 0.04 \\
\hline - The discipline really inspires the very best in me in the way of job performance & -0.3 & 0.001 \\
\hline - The office is not reasonably decorated & -0.2 & 0.03 \\
\hline \multicolumn{3}{|c|}{$\begin{array}{l}\text { Job performance and satisfaction: Less responsible for things happening in the university and I work with little efficiency compared to my first } \\
\text { month of appointment in this university }\end{array}$} \\
\hline - I work with groups of people who expect many different related things from me & 0.3 & 0.002 \\
\hline - In general I perform work that does not suit my values & 0.2 & 0.03 \\
\hline - Number of students you supervised in the last six months & -0.2 & 0.04 \\
\hline \multicolumn{3}{|l|}{ Job commitment: I feel very little loyalty to my discipline } \\
\hline - I often perform tasks that are too boring & 0.3 & $<0.001$ \\
\hline - The university lack facilities for undertaking research & -0.2 & 0.01 \\
\hline - Overall I have too little authority in my work & 0.3 & 0.002 \\
\hline - There is no payment for the excess lecturing hours & 0.5 & $<0.001$ \\
\hline - I think the university looks after its employees in every aspect & -0.2 & 0.02 \\
\hline
\end{tabular}


the employees did not add any stressors that affected their work in the university. All these add strength to the findings of the current study. Findings such as working conditions and workload were expected to be chosen amongst the job stressors. That was mainly due to nature of the job and to the fact that the university is newly established. However, what was not expected was the lack of participation in decision making and authority as well as the lack of promotion and feedback. Newly established institutions usually give the opportunity to their members to give their ideas and suggestions openly which help the overall improvements. In addition, the lack of promotion will definitely affect the success of the organisation.

Of the important weak points was the fact that the study included only employees working in the main building of the university. In order to be generalised, other campuses should be included. In addition, a larger sample size would increase the power of the study. It would be interesting if the study included public and private universities both in Khartoum (the capital of Sudan) and in other cities so as to assess whether the factors were similar or different amongst the Sudanese higher education institutes. The current study could act as a pilot study which provided an idea for the concepts and techniques needed to carry out a larger better-controlled longitudinal study.

\section{Conclusion}

Findings indicated that the employees suffered high levels of job stress. The job stressors affecting the employees included role conflict and ambiguity, lack of promotion opportunities and feedback, lack of participation in decision making, excessive workload, unsatisfactory working conditions and interpersonal relations. The reported stressors were found to have positive and/or negative association with the physical health of the employees, their performance and overall satisfaction about their jobs as well as their commitment. Although the current study did not assess the effect of the stressors on the students themselves, such job stressors and their impact on the organisational performance of employees would eventually affect the students at the university. The university needs to elevate the situation and resolve all the factors affecting the employees which might help in reducing the costs incurred when the trained, well experienced employee and/or the student leave the organisation.

\section{Acknowledgements}

Many thanks to Mrs Mwahib Wedaat Allah and Ms Najat Hassan for their valuable help in photocopying and data collection. We are grateful to the staff of the private university for agreeing to take part in this study; without their help and approval none of this work would have been carried out.

\section{REFERENCES}

Badri, M. A., Selim, H., Alshare, K., Grandon, E. E., Younis, H., \& Abdulla, M. (2006). The baldrige education criteria for performance excellence framework: Empirical test and validation. International Journal of Quality \& Reliability Management, 23, 1118-1157

Ben-Bakr, K. A., Al-Shammari, I. S., \& Jefri, O. A. (1995). Occupational stress in different organizations: A Saudi Arabian survey. Journal of Managerial Psychology, 10, 24-28. doi:10.1108/02683949510085956

Bridger, R. S., Kilminster, S., \& Slaven, G. (2007). Occupational stress and strain in the naval service: 1999 and 2004. Occupational Medicine, 57, 92-97. doi:10.1093/occmed/kql124

Brown, Z. A., \& Uehara, D. L. (2008). Coping with teacher stress: A research synthesis for Pacific education. URL (last checked 2 June 2008). http:www.prel.org

Carmeli, A., \& Gefen, D. (2005). The relationship between work commitment models and employee withdrawal intentions. Journal of Managerial Psychology, 20, 63-86. doi:10.1108/02683940510579731

Chang, K., \& Lu, L. (2007). Characteristics of organizational culture, stressors and wellbeing: The case of Taiwanese organizations. Journal of Managerial Psychology, 22, 549-568. doi:10.1108/02683940710778431

Chen, J. C., Silverthorne, C., \& Hung, J. Y. (2006). Organization communication, job stress, organizational commitment, and job performance of accounting professionals in Taiwan and America. Leadership \& Organization Development Journal, 27, 242-249.

Chevaillier, T. (2000). The changing conditions of higher education teaching personnel. Geneva: Working Paper at the Sectorial Activities Programme International Labour Office.

Conley, S., \& Woosley, S. A. (2000). Teacher role stress, higher order needs and work outcomes. Journal of Educational Administration, 38, 179-201.

Cooke, D., Craven, A. H., \& Clarke, G. M. (1982). Basic statistical computing. London: Edward Arnold.

Daft, R. L. (2006). The new era of management: International Edition. Mason: South-Western Thomson.

Department of Labor. (2008). Occupational outlook handbook: Education administrators. URL (last check 2 August 2008). http://wwww.bls.gov/home.htm

de Smet, P., Sans, S., \& Dramaix, M. (2005). Gender and regional differences in perceived job stress across Europe. European Journal of Public Health, 15, 536-545. doi:10.1093/eurpub/cki028

Dua, J. K. (1994). Job stressors and their effects on physical health, emotional health and job satisfaction in a university. Journal of Educational Adminstration, 32, 59-78.

Fairbrother, K., \& Warn, J. (2003). Workplace dimensions, stress and job satisfaction. Journal of Managerial Psychology, 18, 8-21. doi:10.1108/02683940310459565

Farrugia, C. (1996). A continuing professional development model for quality assurance in higher education. Quality Assurance in Educatin, 4, 28-34. doi:10.1108/09684889610116030

Fevre, M. L., Matheny, J., \& Kolt, G. S. (2003). Eustress, distress, and interpretation in occupational stress. Journal of Managerial Psychology, 18, 726-744. doi:10.1108/02683940310502412

Fotinatos-Ventouratos, R., \& Cooper, C. (2005). The role of gender and social class in work stress. Journal of Managerial Psychology, 20, 14-23. doi:10.1108/02683940510571612

Gmelch, W. H., \& Burns, J. S. (1994). Sources of stress for academic department chairpersons. Journal of Educational Adminstration, 32, 79-94.

Herbert, J. (1997). Fortnightly review: Stress, the brain, and mental illness. BMJ, 315, 530-535. doi:10.1136/bmj.315.7107.530

Johnes, J. (1996). Theory and methodology: Performance assessment in higher education in Britain. European Journal of Operational Research, 89, 18-33.

Johnson, S., Cooper, C., Cartwright, S., Donald, I., Taylor, P., \& Millet, C. (2005). The experience of work-related stress across occupations. Journal of Managerial Psychology, 20, 178-187. doi:10.1108/02683940510579803

Kenny, D. T. (1999). Occupational stress: Reflections on theory and practice. In D. T. Kenny, J. G. Carlson, F. J. McGuigan, \& J. L. Sheppard (Eds.), Stress and health: Research and clinical applications (pp. 16-30). The Netherlands: Gordon Breach/Harwood Academic Publishers.

Kivimäki, M., Leino-Arjas, P., Luukkonen, R., Riihimäki, H., Vahtera, J., \& Kirjonen, J. (2002). Work stress and risk of cardiovascular mortality: Prospective cohort study of industrial employees. BMJ, 325, 857-863. doi:10.1136/bmj.325.7369.857

Koustelios, A., Theodorakis, N., \& Goulimaris, D. (2004). Role ambiguity, role conflict and job satisfaction among physical education 
teachers in Greece. International Journal of Educational Management, $18,87-92$.

Larson, L. L. (2004). Internal auditors and job stress. Managerial Auditing Journal, 19, 1119-1130.

LeGrande, D. (2008). Long work hours, safety and health. URL (last checked 29 April 2008). http://www.cdc.gov/niosh

Lewis, D., Brazil, K., Krueger, P., Lohfeld, L., \& Tjam, E. (2001). Extrinsic and intrinsic determinants of quality of work life. Leadership in Health Services, 14, 9-15.

Liu, C. \& Oppenheim, C. (2006). Competitive intelligence and the development strategy of higher education in Tianjin, China. Information Developmet, 22, 58-63. doi:10.1177/0266666906060091

Lim, V. K. G., \& Teo, T. S. H. (1996). Gender differences in occupational stress and coping strategies among IT personnel. Women in Management Review, 11, 20-28. doi:10.1108/09649429610109299

Love, P. E. D., Irani, Z., Standing, C., \& Themistocleous, M. (2007). Influence of job demands, job control and social support on information systems professionals' psychological well-being. International Journal of Manpower, 28, 513-528.

Manshor, A. T. (2003). Occupational stress among managers: A Malaysian survey. Journal of Managerial Psychology, 18, 622-628.

McCormick, J. (1997). Occupational stress of teachers: Biographical differences in a large school system. Journal of Educational Adminstration, 35, 18-38.

McKenna, M. K., Shelton, C. D., \& Darling, J. R. (2002). The impact of behavioral style assessment on organizational effectiveness: A call for action. Leadership \& Organization Development Journal, 23, 314-322.

Melchior, M., Krieger, N., Kawachi, I., Berkman, L. F., Niedhammer, I., \& Goldberg, M. (2005). Work factors and occupational class disparities in sickness absence: Findings from the GAZEL cohort study. American Journal of Public Health, 95, 1206-1212.

Morris, J., Hassard, J., \& McCann, L. (2006). New organizational forms, human resource management and structural convergence? A study of Japanese organizations. Organization Studies, 27, 1485-1511.

Mutula, S. M. (2001) Financing public universities in eastern and southern Africa: Implications for information services. The Bottom Line: Managing Library Finances, 14, 116-131.

Nhundu, T. J. (1999). Determinants and prevalence of occupational stress among Zimbabwean school administrators. Journal of Educational Adminstration, 37, 256-272.

Noblet, A. (2003). Building health promoting work settings: Identifying the relationship between work characteristics and occupational stress in Australia. Health Promotion International, 18, 351-359.

Nwadiani, M. (2006). Level of perceived stress among lectures in Nigerian universities. Journal of Instructional Psychology. URL (last checked 2 June 2008). http://www.thefreelibrary.com/

Nyssen, A. S., Hansez, I., Baele, P., Lamy, M., \& De Keyser, V. (2003). Occupational stress and burnout in anaesthesia. British Journal of Anaesthesia, 90, 333-337. doi:10.1093/bja/aeg058

Punnett, B. J., Duffy, J. A., Fox, S. et al. (2007). Career success and satisfaction: A comparative study in nine countries. Women in $\mathrm{Ma}$ - nagement Review, 22, 371-390. doi:10.1108/09649420710761446

Rees, C. J., \& Redfern, D. (2000). Recognising the perceived causes of stress-A training and development perspective. Industrial and Commercial Training, 32, 120-127.

Reskin, A. (2008). Podcast transcript for working with stress. URL (last checked 29 April 2008). http://online.sagepub.com/

Rowley, J. (1996). Motivation and academic staff in higher education. Quality Assurance in Educatin, 4, 11-16. doi:10.1108/09684889610125814

Sadri, G. (1997). An examination of academic and occupational stress in the USA. International Journal of Educational Management, 11, 32-43. doi:10.1108/09513549710155438

Savery, L. K., \& Luks, J. A. (2001). The relationship between empowerment, job satisfaction and reported stress levels: Some Australian evidence. Leadership \& Organization Development Journal, 22, 97-104. doi:10.1108/01437730110389247

Sharpley, C. F., Reynolds, R., \& Acosta, A. (1996). The presence, nature and effects of job stress on physical and psychological health at a large Australian university. Journal of Educational Adminstration, 34, 73-86.

Smith, A. (2000). The scale of perceived occupational stress. Occupational Medicine, 50, 294-298.

Sotirakou, T. (2004). Coping with conflict within the entrepreneurial university: Threat or challenge for heads of departments in the UK higher education context. International Review of Administrative Sciences, 70, 345-372.

Stress, (2008). More information: Stress at work. URL (last checked 2 August 2008).

http://www.safetyline.wa.gov.au/newsite/worksafe/default.html

Tennant, J. (2007). Work-related stress: The experiences of polytechnic teachers: Literature review. URL (last checked 19 June 2008). http://www.coda.ac.nz/whitireia studsupdi/2

Timms, C., Graham, D., \& Cottrell, D. (2007). “I just want to teach”: Queensland independent school teachers and their workload. Journal of Educational Adminstration, 45, 569-586.

The United Nations Educational, Scientific and Cultural Organization (UNESCO). (1993). Women in higher education management. Paris: UNESCO.

Tytherleigh, M. Y., Webb, C., Cooper, C. L., \& Ricketts, C. (2005). Occupational stress in UK higher education institutions: A comparative study of all staff categories. Higher Education Research \& Development, 24, 41-61. doi:10.1080/0729436052000318569

Vakola, M., \& Nikolaou, I. (2005). Attitudes towards organizational change: What is the role of employees' stress and commitment? Employee Relations, 27, 160-174. doi:10.1108/01425450510572685

van der Hek, H. \& Plomp, H. N. (1997). Occupational stress management programmes: A practical overview of published effect studies. Occupational Medicine, 47, 133-141. doi:10.1093/occmed/47.3.133

Venables, K. M., \& Allender, S. (2006). Occupational health needs of universities: a review with an emphasis on the United Kingdom. Occupational \& Environmental Medicine, 63, 159-156.

\section{Abbreviations}

Person-environment fit theory $=\mathrm{PE}$. 